\title{
Preference monitoring of Bactrocera spp. through installation of methyl eugenol traps at different heights in Jujube orchard
} \author{
Abdul wahab ${ }^{4}$ \\ 1. Department of Entomology, Sindh Agriculture University Tando Jam-Pakistan \\ 2. Agriculture Research Institute Balochistan (Agriculture Department)-Pakistan \\ 3. Government College University Hyderabad-Pakistan \\ 4. Agriculture Department water management Baluchistan Quetta.. \\ *Corresponding author's email: bksolangi@gmail.com
}

Junaid Ahmed Vistro ${ }^{1}$, Bhai Khan Solangi ${ }^{*}$, Muhammad Saleem², Imroz Solangi ${ }^{3}$, Muhammad Akbar Lashari', Abdul Raoof Khan ${ }^{2}$, Zulfiqar Ali Mastoi ${ }^{2}$, Abdul Rehman ${ }^{2}$, Ghulam Hussain Alizai $^{2}$ and

Citation

Junaid Ahmed Vistro, Bhai Khan Solangi, Muhammad Saleem, Imroz Solangi, Muhammad Akbar Lashari, Abdul Raoof Khan, Zulfiqar Ali Mastoi, Abdul Rehman and Ghulam Hussain Alizai. Preference monitoring of Bactrocera spp. through installation of methyl eugenol traps at different heights in Jujube orchard. Pure and Applied Biology. Vol. 10, Issue 4, pp1141-1147. http://dx.doi.org/10.19045/bspab.2021.100120

\begin{tabular}{llll}
\hline \hline Received: 26/10/2020 & Revised: 22/01/2021 & Accepted: 26/01/2021 & Online First: 28/01/2021 \\
\hline
\end{tabular}

\section{Abstract}

An experiment was conducted during the years (2016 to 2017) on preference monitoring of Bactrocera spp. through installation of methyl eugenol traps at different heights in jujube orchard. The pheromone traps baited with lure toxicant mixture (95\% methyl eugenol + Thiodan insecticide) were installed at $(\mathrm{T} 1)=$ ground surface, $(\mathrm{T} 2)=1 \mathrm{~m}$ height. $(\mathrm{T} 3)=2 \mathrm{~m}$ height and $(\mathrm{T} 4)=3 \mathrm{~m}$ height. The effect of different heights of methyl eugenol pheromone traps on the male-adult $B$. zonata and $B$. dorsalis catches was statistically significant $(\mathrm{P}<0.05)$; and the fruit fly catches in traps varied significantly during 26-12-16 to $10-04-17(\mathrm{P}<0.05)$. The highest B. zonata catches $(61.38)$ were monitored in traps installed at $2 \mathrm{~m}$ height; while the weekly $B$. zonata trap catches simultaneously decreased to (51.35), (43.03) and (38.09) at trap heights of $3 \mathrm{~m}, 1 \mathrm{~m}$ and $0 \mathrm{~m}$ (surface), respectively. The average weekly trap catches of $B$. zonata were 83.7 . The maximum weekly $B$. dorsalis catches $(0.49)$ were found in traps installed at $2 \mathrm{~m}$ height; while the weekly $B$. dorsalis trap catches decreased to $0.43,0.36$ and 0.29 when the traps were installed at $3 \mathrm{~m}, 1 \mathrm{~m}$ and $0 \mathrm{~m}$ (surface) heights, respectively. The average weekly trap catches of $B$. dorsalis were 7.65. It was concluded that the methyl eugenol pheromone traps were most effective when installed at $2 \mathrm{~m}$ height; while traps installed at $3 \mathrm{~m}$ and $1 \mathrm{~m}$ height could not catch $B$. zonata and $B$. dorsalis more than the surface installed traps. The B. zonata starts its rapid development from the April with certain fluctuation.

Keyword: Preference; Monitoring; Bactrocera; Methyl eugenol; Traps; Jujube orchard Introduction

Jujube, Ziziphus jujuba Mill., locally called 'ber' and belongs to the family Rhamnaceae, is an indigenous fruit of China and South Asia, produced in temperate regions such as China, India, Pakistan, Syria, Australia and Malaysia. Jujube requires a hot and dry climate. It can survive temperatures of up to $50^{\circ} \mathrm{C}$ and with such a tolerance for heat it is of little surprise that it does not do well when temperatures approach freezing. Jujube 
fruits are deciduous and can tolerate cold winters to $28^{\circ} \mathrm{F}$. They have a low chilling requirement allowing them to produce fruit in areas having mild winters. Long, hot summers are necessary to ripen good fruit crops. Pollination is done by bees and flies. In Pakistan, jujube is extensively cultivated, but thrive best under ecological conditions of Hyderabad, Khairpur, Multan, Sargodha and Lahore Divisions. Hyderabad is famous for producing quality fruit for export to Middle East. The tree is hard, drought resistant and can thrive in poor alkaline tracts without much irrigation and care, and survive on soils where other fruit trees cannot [1]. Ber or jujube, a common fruit grown in the warm subtropical regions of Pakistan, belongs to the genus Zizyphus of family Rhamnaceae [2]. In Pakistan, Ber is produced over an area of 5425 hectares with an annual production of 27950 tones [3].

Fruit flies of genus Bactrocera are commonly associated to mango, citrus and guava orchards [4]. Fruit flies (Diptera: Tephritidae) are considered the most destructive insect pests of fruits and vegetables in the world. The hosts of these flies belong to a wide variety of families of plants and include many major commercial crops [5]. Without flies control, direct damage has been reported from 30 to $80 \%$ depending on the fruit, variety, location and fruit season [6]. Fruit fly, Bactrocera spp. (Diptera: Tephritidae) are one of potential pests that is very detrimental to horticultural production reducing crop yield either through quantitatively or quality [7]. Among 400 species of fruit flies distributed all over the world, Bactrocera zonata (Saunder), Bactrocera dorsalis (Hendel) is the most destructive pest [8]. They over winter at adult stage and impose damage by infesting fruits. Female flies lay eggs in soft and tender fruit tissues and subsequently maggots nourish inside the host fruit [9]. In Pakistan 11 species of genus Bactrocera, out of total 43 species, have been marked out from Pakistan.
Among these are $B$. zonata, B. dorsalis and $B$. cucurbitae are the most prominent [10] infesting apple (Malus domestic), bitter gourd, (Momordica charantia), guava (Psidium guajava), ber (Ziziphus mauritiana), mango (Mangifera indica), muskmelon (Cucumis melon) and snake gourd (Trichosanthes cucumerina) [11].

Severity of damage is caused by three fruit fly species namely, Bactrocera zonata (Saunder), Carpomia vasuviana (Costa) and Bactrocera cucurbitae (Coquillett), from the time of fruit setting up to harvesting. All above mentioned fruit fly species inflict colossal losses which ultimately confine the fruit production involve deployment of large numbers of Jackson traps baited with highly attractive male-specific lures [12]. For example, methyl eugenol (ME; 4-allyl-1, 2dimethoxybenzene-carboxylate) and cuelure (C-L; 4-(p-acetoxyphenyl)-2butanone) are used for detection of oriental fruit by, Bactrocera dorsalis (Hendel) and melon by, Bactrocera cucurbitae (Coquillett), respectively. However, an important environmental concern of these trapping systems is that detection traps are currently deployed in association with toxic liquid insecticide formulations such as naled [13].

The current study was carried to determine the population dynamics of various fruit flies' species in term of identification on different varieties of beer. The importance of the present survey for fruit flies in beer orchard was exploited for managing the population densities of fruit flies through integrated pest management program. In different orchards of jujube, the study was useful in managing the population densities of fruit flies and their integrated pest management (IPM) programs.

\section{Materials and Methods}

The experiment was conducted during the year 2016-17 for the monitoring of Bactrocera spp. on an area of 10 acres of jujube orchard farm, Agriculture Research Institute (ARI) Tandojam. The male adult population of fruit flies was recorded 
weekly through pheromone trap baited with lure toxicant mixture (95\% methyl eugenol+ 5\% Thiodan insecticide).

The experiment was conducted to observe the fruit fly catches by hanging fruit fly traps at different heights on jujube trees.

\section{Treatments}

$\mathrm{T}_{1}=$ Pheromone traps installed on ground surface

$\mathrm{T}_{2}=$ Pheromone traps installed at 1-meter height

$\mathrm{T}_{3}=$ Pheromone traps installed at 2 meters height

$\mathrm{T}_{4}=$ Pheromone traps installed at 3 meters height

The experiment was replicated five times. The pheromone traps were replenished after 15 days to keep fresh chemical for attraction of the fruit flies. Killed male flies in traps were counted and species were identified at weekly interval. The collected data was statistically analysis using statix. 8.1 version.

\section{Results}

The study was conducted during season, 2016-17. To examined the preference monitoring of Bactrocera spp. on an area of 10 acres of jujube orchard. The trial was conducted at the area of Agriculture Research Institute (ARI) Tandojam. The experiment included five replications and four applications viz., $\mathrm{T}_{1}=$ Pheromone traps installed on ground surface, $\mathrm{T}_{2}=$ Pheromone traps installed at 1-meter height, $\mathrm{T}_{3}=$ Pheromone traps installed at 2 meters height and $\mathrm{T}_{4}=$ Pheromone traps installed at 3 meters height. The treatment observations were recorded on different weeks from (26-12-16 to 10-04-17).

Weekly population of $B$. zonata at different heights under varied temperature and humidity at Jujube Orchard Tandojam

The (Table 1) showed the observations that effect of different heights of methyl eugenol pheromone traps (treatments) on the male-adult $B$. zonata catches was statistically significant $(\mathrm{P}<0.05)$; and the $B$. zonata catches in traps varied significantly during different weeks of
2016-17 $(\mathrm{P}<0.05)$. The treatment effect showed that highest $B$. zonata catches (83.7) were monitored in traps installed at $2 \mathrm{~m}$ height (T3); while the B. zonata trap catches simultaneously decreased to (74.66), (66.69) and (62.54) at trap heights of $3 \mathrm{~m}$ (T4), $1 \mathrm{~m}$ (T2) and $0 \mathrm{~m}$ (surface, T1), respectively. The average weekly traps catch of B. zonata were 3.72 and the methyl eugenol pheromone traps were most effective when installed at $2 \mathrm{~m}$ height; while traps installed at $3 \mathrm{~m}$ and $1 \mathrm{~m}$ height could not catch $B$. zonata male adults more than the surface installed traps. The record of sixteen weeks maleadult monitoring of $B$. zonata shows that the insect population was higher in $\mathrm{T}_{3}$ (83.7) and while the least trap catches were observed in the $\mathrm{T}_{4}$ (74.66), $\mathrm{T}_{2}$ (66.69) and $\mathrm{T}_{1}(62.54)$. The $B$. zonata starts its rapid development from the 03-04-17 and sustains up to the 10-04-17 towards with certain fluctuation. This indicates that there is linear association of $B$. zonata population with the temperature, when its sky-high population was recorded during 2017; while the population declined in the weeks of low temperature. During the years of study 2016-17 the mean temperature was $23.03^{\circ} \mathrm{C}$, suggesting a linear relationship of temperature with the insect population buildup. The interactive effect between different parameters indicated that the highest $B$. zonata weekly population on average was 83.7 in 10-0417 when the methyl eugenol pheromone traps were installed at $2 \mathrm{~m}$ height (T3); while the minimum insect population of (16.07) was monitored in 23-01-17 at o m (surface) height (T1).

Pearson's correlation among $B$. zonata population and abiotic factors

Correlation estimates between $B$. zonata population and abiotic factors (temperature and relative humidity) was worked out and presented in (Table 2). There was significant and positive correlation (R2= $0.8476^{*}$ ) between $B$. zonata population and temperature. Whereas, negative and nonsignificant correlation $\left(\mathrm{R} 2=-0.5343^{\mathrm{NS}}\right)$ 
was analyzed among the $B$. zonata population and relative humidity. This indicates that the $B$. zonata population was linearly increased by the elevation of temperature and the $B$. zonata population did not fluctuated by the relative humidity up down.

Table 1. Weekly population of $B$. zonata at different heights under varied temperature and humidity at Jujube Orchard Tandojam

\begin{tabular}{|c|c|c|c|c|c|c|}
\hline Week & T1= Surface & $\begin{array}{c}\text { T2= 1-meter } \\
\text { height }\end{array}$ & $\begin{array}{c}\text { T3= 2-meter } \\
\text { height }\end{array}$ & $\begin{array}{c}\text { T4= 3-meter } \\
\text { height }\end{array}$ & $\begin{array}{c}\text { Temperature } \\
\left({ }^{\mathbf{C}} \mathbf{C}\right)\end{array}$ & $\begin{array}{c}\text { R.H } \\
\text { \% }\end{array}$ \\
\hline $\mathbf{2 6 - 1 2 - 1 6}$ & 31.9 & 38.71 & 59.51 & 49.91 & 25 & 51 \\
\hline $\mathbf{0 2 - 0 1 - 1 7}$ & 52.35 & 58.94 & 79.85 & 69.97 & 25 & 47 \\
\hline $\mathbf{0 9 - 0 1 - 1 7}$ & 36.21 & 41.94 & 60.47 & 49.85 & 23 & 48 \\
\hline $\mathbf{1 6 - 0 1 - 1 7}$ & 26.11 & 31.84 & 50.37 & 39.75 & 22.8 & 47 \\
\hline $\mathbf{2 3 - 0 1 - 1 7}$ & 16.07 & 21.74 & 40.33 & 29.71 & 20 & 49 \\
\hline $\mathbf{3 0 - 0 1 - 1 7}$ & 22.97 & 26.84 & 45.43 & 34.61 & 21.3 & 46 \\
\hline $\mathbf{0 6 - 0 2 - 1 7}$ & 19.87 & 23.74 & 42.33 & 31.51 & 19.5 & 46 \\
\hline $\mathbf{1 3 - 0 2 - 1 7}$ & 33.97 & 38.84 & 57.43 & 46.61 & 21 & 49 \\
\hline $\mathbf{2 0 - 0 2 - 1 7}$ & 26.92 & 31.59 & 49.18 & 39.56 & 21.7 & 47 \\
\hline $\mathbf{2 7 - 0 2 - 1 7}$ & 26.92 & 31.59 & 49.18 & 39.56 & 23 & 45 \\
\hline $\mathbf{0 6 - 0 3 - 1 7}$ & 37.01 & 41.69 & 59.24 & 49.66 & 22.4 & 44 \\
\hline $\mathbf{1 3 - 0 3 - 1 7}$ & 47.11 & 51.79 & 69.34 & 59.76 & 22 & 42 \\
\hline $\mathbf{2 0 - 0 3 - 1 7}$ & 52.31 & 56.99 & 74.54 & 64.96 & 24.2 & 44 \\
\hline $\mathbf{2 7 - 0 3 - 1 7}$ & 56.54 & 60.89 & 78.64 & 68.86 & 25 & 45 \\
\hline $\mathbf{0 3 - 0 4 - 1 7}$ & 60.64 & 64.79 & 82.54 & 72.76 & 25.6 & 44 \\
\hline $\mathbf{1 0 - 0 4 - 1 7}$ & 62.54 & 66.69 & 83.7 & 74.66 & 27 & 42 \\
\hline Mean & 38.09 & 43.03 & 61.38 & 51.35 & 23.03 & 46 \\
\hline SE & 3.78 & 3.75 & 3.72 & 3.81 & 0.53 & 0.63 \\
\hline
\end{tabular}

Table 2. Pearson's correlation among $B$. zonata population and abiotic factors

\begin{tabular}{|c|c|}
\hline Variable & B. zonata population \\
\hline Temperature & $0.8476^{* *}$ \\
\hline Relative humidity & $-0.5343^{\mathrm{NS}}$ \\
\hline
\end{tabular}

Weekly population of $B$. dorsalis at different heights under varied temperature and humidity at Jujube Orchard Tandojam

The (Table 3) showed the observations that effect of different heights of methyl eugenol pheromone traps (treatments) on the male-adult $B$. dorsalis catches was statistically significant $(\mathrm{P}<0.05)$; and the $B$. dorsalis catches in traps varied significantly during different weeks of 2016-17 $(\mathrm{P}<0.05)$. The treatment effect showed that highest $B$. dorsalis catches (4.96) were monitored in traps installed at 2 m height (T3); while the $B$. dorsalis trap catches simultaneously decreased to 3.89 , 3.16 and 2.66 at trap heights of $3 \mathrm{~m}$ (T4), $1 \mathrm{~m} \mathrm{(T2)} \mathrm{and} 0 \mathrm{~m}$ (surface, T1), respectively. The average weekly traps catch of $B$. dorsalis were 0.49 and the methyl eugenol pheromone traps were most effective when installed at $2 \mathrm{~m}$ height; while traps installed at $3 \mathrm{~m}$ and 1 $\mathrm{m}$ height could not catch $B$. dorsalis male adults more than the surface installed traps.

The record of sixteen weeks male-adult monitoring of $B$. dorsalis shows that the insect population was higher in $\mathrm{T}_{3}(7.65)$ and while the least trap catches were observed in the $\mathrm{T}_{4}(6.22), \mathrm{T}_{2}$ (4.74) and $\mathrm{T}_{1}$ (3.53). The $B$. dorsalis starts its rapid development from the 03-04-17 and sustains up to the 10-04-17 towards with certain fluctuation. This indicates that there is linear association of $B$. dorsalis 
population with the temperature, when its sky-high population was recorded during 2017; while the population declined in the weeks of low temperature. During the years of study 2016-17 the mean temperature was $23.03^{\circ} \mathrm{C}$, suggesting a linear relationship of temperature with the insect population buildup. The interactive effect between different parameters indicated that the highest $B$. dorsalis weekly population on average was 7.65 in 03-04-17 when the methyl eugenol pheromone traps were installed at $2 \mathrm{~m}$ height (T3); while the minimum insect population of 1.7 was monitored in 30-0117 at $0 \mathrm{~m}$ (surface, T1).

Table 3. Weekly population of $B$. dorsalis at different heights under varied temperature and humidity at Jujube Orchard Tandojam

\begin{tabular}{|c|c|c|c|c|c|c|}
\hline Week & $\begin{array}{c}\text { T1 }= \\
\text { Surface }\end{array}$ & $\begin{array}{c}\text { T2= 1-meter } \\
\text { height }\end{array}$ & $\begin{array}{c}\text { T3= 2-meter } \\
\text { height }\end{array}$ & $\begin{array}{c}\text { T4= 3-meter } \\
\text { height }\end{array}$ & $\begin{array}{c}\text { Temperature } \\
\left({ }^{\mathbf{C}} \mathbf{C}\right)\end{array}$ & R.H\% \\
\hline $\mathbf{2 6 - 1 2 - 1 6}$ & 1.88 & 2.34 & 4.31 & 3.05 & 25 & 51 \\
\hline $\mathbf{0 2 - 0 1 - 1 7}$ & 1.85 & 1.95 & 3.75 & 2.5 & 25 & 47 \\
\hline $\mathbf{0 9 - 0 1 - 1 7}$ & 1.95 & 2.05 & 3.95 & 2.63 & 23 & 48 \\
\hline $\mathbf{1 6 - 0 1 - 1 7}$ & 1.93 & 2.03 & 3.92 & 2.61 & 22.8 & 47 \\
\hline $\mathbf{2 3 - 0 1 - 1 7}$ & 1.91 & 2.01 & 3.89 & 2.59 & 20 & 49 \\
\hline $\mathbf{3 0 - 0 1 - 1 7}$ & 1.7 & 2.05 & 2.8 & 2.4 & 21.3 & 46 \\
\hline $\mathbf{0 6 - 0 2 - 1 7}$ & 1.79 & 2.16 & 2.95 & 2.53 & 19.5 & 46 \\
\hline $\mathbf{1 3 - 0 2 - 1 7}$ & 1.77 & 2.14 & 2.93 & 2.51 & 21 & 49 \\
\hline $\mathbf{2 0 - 0 2 - 1 7}$ & 1.78 & 2.15 & 2.94 & 2.52 & 21.7 & 47 \\
\hline $\mathbf{2 7 - 0 2 - 1 7}$ & 1.85 & 1.95 & 3.85 & 2.53 & 23 & 45 \\
\hline $\mathbf{0 6 - 0 3 - 1 7}$ & 4.48 & 5.12 & 7 & 5.88 & 22.4 & 44 \\
\hline $\mathbf{1 3 - 0 3 - 1 7}$ & 4.72 & 5.4 & 7.39 & 6.2 & 22 & 42 \\
\hline $\mathbf{2 0 - 0 3 - 1 7}$ & 4.68 & 5.35 & 7.33 & 6.15 & 24.2 & 44 \\
\hline $\mathbf{2 7 - 0 3 - 1 7}$ & 3.35 & 4.5 & 7.25 & 5.9 & 25 & 45 \\
\hline $\mathbf{0 3 - 0 4 - 1 7}$ & 3.53 & 4.74 & 7.65 & 6.22 & 25.6 & 44 \\
\hline $\mathbf{1 0 - 0 4 - 1 7}$ & 3.5 & 4.71 & 7.59 & 6.17 & 27 & 42 \\
\hline Mean & 2.66 & 3.16 & 4.96 & 3.89 & 23.03 & 46 \\
\hline SE & 0.29 & 0.36 & 0.49 & 0.43 & 0.53 & 0.63 \\
\hline
\end{tabular}

Pearson's correlation among $\boldsymbol{B}$. dorsalis population and abiotic factors

Correlation estimates between $B$. dorsalis population and abiotic factors (temperature and relative humidity) was worked out and presented in (Table 4). There was significant and positive correlation $\left(\mathrm{R} 2=0.5112^{*}\right)$ between $B$. dorsalis population and temperature.
Whereas, negative and non-significant correlation $\left(\mathrm{R} 2=-0.7645^{\mathrm{NS}}\right)$ was analyzed among the $B$. dorsalis population and relative humidity. This indicates that the B. dorsalis population was linearly increased by the elevation of temperature and the B. dorsalis population did not fluctuated by the relative humidity up down.

Table 4. Pearson's correlation among $B$. dorsalis population and abiotic factors

\begin{tabular}{|c|c|}
\hline Variable & B. dorsalis population \\
\hline Temperature & $0.5112^{* *}$ \\
\hline Relative humidity & $-0.7645^{\mathrm{NS}}$ \\
\hline
\end{tabular}

\section{Discussion}

The present research was conducted for the monitoring of Bactrocera Spp. on an area of 10 acres of jujube orchard farm was conducted at the area of Agriculture Research Institute (ARI) Tandojam, 
during 2016-2017.During the present finding it was examined that $B$. zonata starts its rapid development from the 0304-17 and sustains up towards with certain fluctuation. This indicated that there is linear association of B. zonata population with the temperature, when its sky-high population was recorded during week of April while the population declined in the weeks of low temperature. Essam et al. [14] determined the effectiveness of the field performance of fiber blocks were impregnated with the solution of Sumithion 95\% (mixed with methyl eugenol in the ratio of $1: 4)$, Sumithion $50 \%$ under field conditions. Efficiency (as lured and killed male fruit flies) of all application deceased over time regardless of the area. The data showed that Sumithion (mixed with methyl eugenol in the ratio of 1:4) and sticky double sheets were significantly impactive than other applications. It was suggested that Sumithion mixture can be used successfully in $B$. zonata male annihilation technique. Similarly, Kumar and Ktamath [15] examined that attraction of diverse species of fruit flies to diverse coloured traps in jujube orchard. Data showed that yellow and transparent traps attracted significant highly number of $B$. correcta in guava followed by green and orange coloured traps in guava (3.79 and 3.75 fruit flies/trap/week, respectively) black coloured traps in mango (3.88 fruit flies/trap/week) were attractive to $B$. dorsalis. B. zonata was attracted to red coloured traps (3.75 fruit flies/trap/week) in mango ecosystem. When total fruit flies irrespective of species were considered, yellow colour traps were most attractive in guava (71.91 fruit flies/trap/week) while black colour traps (8.68 fruit flies/trap/week). From another study Hasnain et al. [16] observed to evaluate the fruit fly capture in traps at different heights by using methyl eugenol. The results showed that the maximum average male fruit flies (515) were caught at the height of 5 feet, whereas, the minimum
(315) were caught at the ground level. These results suggest that for the monitoring of fruit flies, the methyl eugenol traps should be hanged at the height of 5 feet from ground level to get the maximum counts of fruit flies.

\section{Conclusion}

It could be concluded that methyl eugenol pheromone traps were most effective when installed at $2 \mathrm{~m}$ height; while traps installed at $3 \mathrm{~m}$ and $1 \mathrm{~m}$ height could not catch $B$. zonata and $B$. dorsalis more than the surface installed traps. The $B$. zonata starts its rapid development from the month of April; while B. dorsalis starts flaring up in April and then reached its peak population. The B. dorsalis is basically the mango fruit fly and its population were more associated with the mango season rather to associate its population with the abiotic factors. Generally, the $B$. zonata population was markedly higher than the population of $B$. dorsalis.

\section{Authors' contributions}

Conceived and designed the experiments JA Vistro \& BK Solangi, Performed the experiments: M Saleem, I Solangi \& MA Lashari, Analyzed the data: AR Khan \& ZA Mastoi, Contributed reagents/ materials/ analysis tools: A Rehman \& GH Alizai, Wrote the paper: JA Vistro \& BK Solangi.

\section{References}

1. Khushk (2002). Studies on baits and dust formulations of insecticides against fruit fly (Diptera: Tephritidae) on melon (Curcumis melo) under semi-arid conditions of Dera Ismail Khan. Pak J Biol Sci 4: 334-335.

2. Anonymous (2003-2004). Nontraditional control of fruit flies in guava orchards in D. I. Khan. Pak J of Agric Res 17: 195-196.

3. Anonymous (2011). Fruit, vegetables and condiments statistics of Pakistan. Govt. of Pakistan, Finance Division, Economic Adviser's wing, Islamabad, pp. 1-2. 
4. Irshad \& Jilani (2003). Economic Survey of Pakistan. Government of Pakistan, Ministry of Food and Agriculture, Islamabad, Pakistan.

5. Salem \& Abd-El- Salam (2013). Geographic distribution, host fruit and parasitoids of African fruit fly pest Ceratitis anonae, Ceratitis cosyra, Ceratitis fasciventris and Ceratitis rosa (Diptera: Tephritidae) in Kenya. Annals of the Entomol Soc of Am 99(2): 261-278.

6. Mwatawala et al. (2006). Studies on the control of Bactrocera zonata (Saunders) by male annihilation techniques in two locations. $J$ of Toxicol and Sci 5(2): 48-54.

7. Rouse et al. (2005). Copeland et al., 2006. Changes in height of pheromone traps affect the capture of male fruit fly, Bactrocera spp. (Diptera: Tephritidae). J of Environ and Agric Sci 10: 33-39.

8. Verghese et al. (2006). Bacterocera zonata the predominant fruit fly species in mango, citrus and guava orchards. Management of fruit fly in Pakistan. Pest Management. Research Programme NARC, Islamabad, Pakistan.

9. Abdullah et al. (2002). Management of fruit flies (Diptera: Tephritidae) of the most erishable fruits. Entomol Res 35: 79-84.

10. Abdullah \& Latif (2001). Ber orchard: an economical enterprise. DAWN
Internet Edition, 23rd December, 2002.

11. Khan et al. (2005). Attraction of fruit flies to different colours of methyl eugenol traps in guava and mango orchards. Karnataka J Agric Sci 20(4): 749-751.

12. Macarthur \& Wilson (1963). An equilibrium theory of insular zoogeography. Evol 17: 373- 387.

13. Vargas et al. (2009). Seasonality and host utilization of the invasive fruit fly, Bactrocera invadens (Dipt. Tephritidae) in Central Tanzania. $J$ of Appl Entomol 130(9-10): 530-537.

14. Essam et al. (2013). Adjustment of field cage methodology for testing food attractants for fruit flies (Diptera: Tephritidae). Annals Entomol Soc of Am 98(3): 402-408.

15. Kumar \& Ktamath (2007). Field evaluation and efficacy of different natural and sex attractant traps for attracting the adults of med and peach flies, Ceratitis capitata (Wied.) and Bactrocera zonata (Saunders). Canadian J of Plant Protec 1(5): 167171.

16. Hasnain et al. (2017). Captures of Bactrocera males (Diptera: Tephritidae) in parapheromone-baited traps: a comparison of liquid versus solid formulations. Proc Hawaii Entomol Soc 74: 80-66. 